\title{
Intervalling-Effect Bias and Competition Policy
}

\author{
Panagiotis N. Fotis ${ }^{1, *}$, Victoria Pekka-Oikonomou ${ }^{2}$ and Michael L. Polemis ${ }^{3}$ \\ ${ }^{1}$ General Directorate for Competition, Hellenic Competition Commission, Athens, Greece \\ ${ }^{2}$ Department of Business Administration, University of Piraeus, Piraeus, Greece \\ ${ }^{3}$ Department of Economics, University of Piraeus, Piraeus, Greece
}

\begin{abstract}
The purpose of this paper is twofold. First, it aims to investigate whether the security's systematic risk beta estimates change as the infrequent trading phenomenon appears. Second, it attempts to provide useful insight on the impact of mergers and acquisitions on competition policy. For this reason, we employ the models of Scholes and Williams (1977), Dimson (1979), Cohen et al. (1983a) and Maynes and Rumsey (1993) on a small stock exchange with thickly infrequent trading stocks. The empirical results reveal that for some securities the models employed by Scholes and Williams (1977) and Cohen et al. (1983a) improve the biasness of the Ordinary Least Squares Market Model (Maynes and Rumsey, 1993). We argue that competitors gain while merged entities loose or at least do not gain from the clearness of the investigated mergers.
\end{abstract}

Keywords: Intervalling-effect bias, Beta risk measurement, Infrequent trading phenomenon, Mergers and Acquisitions, Competition policy.

\section{INTRODUCTION}

The intervalling-effect bias in security's beta estimates denotes the sensitivity of the beta to the length of the interval return (daily, monthly or yearly). Empirically, estimated beta values are systematically changed as the return interval is varied if Independent and Identically Distributed (IID) additive assumption is violated. ${ }^{1}$ The seminal paper examining intervallingeffect bias is attributed to Fama (1970).

Scholes and Williams (1977) and Dimson (1979) addressed the intervalling-effect bias slightly differently and showed the bias in beta caused by infrequent trading phenomenon. The latter appears when some stocks do not trade daily in the stock exchange. In such a case, the estimated variance and co-variance of the stock performance is positively correlated with their trade frequency.

The link between the security's beta estimates and inferences for competition policy has also been explored in the literature. According to this link critical role plays the movement of securities' residuals during the examined time interval which is affected by the

${ }^{*}$ Address correspondence to this author at the P. loakim 5, 12132 Peristeri Attikis, Greece; Tel: + 30-210-5712588; Fax: + 30-210-5712588;

E-mail: p1972fo@gmail.com

${ }^{1}$ Levhari and Levy (1977) proved that the expected value of the estimated beta of aggressive stocks (beta greater than one) increases as the time interval increases and hence be over- estimated (a positive monotonicity outcome in time interval). The opposite happening for defensive stocks (Levy-Levhari hypothesis) event under scrutiny (Event study methodology). If the event constitutes an announcement or a notification of Mergers \& Acquisitions (M\&As), a researcher has the ability to inference potential anti or pro competitive effects of the scrutinized M\&As. Cox and Portes (1998) portray a detailed clarification of the competitive outcomes for M\&As with infrequent trading phenomenon.

In the literature there is a vast majority of articles which deal with the above mentioned research areas. In particular and regarding the intervalling-effect bias in security's beta estimates, Hong and Satchell (2014) examine Capital Asset Pricing Model (CAPM) in which errors are correlated with exogenous factors and consider the evaluation of betas on current time. The authors show, inter alia, that the intervalling effect bias process produces extremely good results for short time intervals and that beta estimates are monotonic to time interval. Milonas and Rompotis (2013) show that small cap Exchange Traded Funds (ETFs) have greater betas than large cap ETFs, while Ordinary Least Square (OLS) beta of all the ETFs increases as the interval return is lengthened regardless of the degree of capitalization.

The most commonly empirical models which are dealing with infrequent trading phenomenon are attributed to Cohen et al. (1983a) and the Market Model by Maynes and Rumsey (1993). Armitage and Brzeszczynski (2011) argue that OLS method tends to overestimate the beta coefficients than the $\mathrm{ARCH}$ models. Sercu, Vanderbroek and Vinaimont (2008) find 
that OLS exhibits the highest bias and lowest standard errors, while the model proposed by Scholes and Whilliams (1977) delivers the lowest bias and the highest standard errors.

Diacogiannis and Makri (2008) examine with OLS the intervalling effect bias for a number of thinly traded securities on the Athens Stock Exchange (ASE) and conclude that the bias appears. ${ }^{2}$ They also compare the beta estimates which are derived from the Scholes and Williams (1977), Cohen et al. (1983a) and Maynes and Rumsey (1993) models and state that there are no statistically significant differences between the mean beta estimates. $^{3}$

As it concerns the literature regarding the anti or pro competitive effects of M\&As, Rahim and Pok (2013) use an event study methodology and explore the short - run wealth effects of M\&As announcements in Malaysia during the period from 2001 to 2009. They find positive market reactions for both targets and bidding firms. Fotis and Polemis (2012a) find mixed results by investigating the short - run effects of critical mergers in Greece the last decade, while Fotis, Polemis and Zevgolis (2011) examine 13 requested derogations from suspension during the period 19952008 by applying and assessing the results of three different event study methodologies (market model, mean adjusted return model and market adjusted return model). They found that the average abnormal and cumulative returns of the requested firms are positive and statistical significant.

Furthermore, Duso, Gugler and Yurtoglou (2010) infer that a long time window around the announcement merger date ( 25 or 50 days prior to the event) increases the ability to capture mergers' ex post profitability by using accounting data (see also Mueller 1980). Bharba (2008) infers that potential targets of M\&As experience a statistically significant wealth gain estimated to $0.59 \%$ over the three day event window, while Duso, Neven and Röller (2007) and Aktas, de Bodt and Roll (2007) thoroughly investigated the anti or pro competitive effects of M\&As under the European merger control regime. ${ }^{4}$

\footnotetext{
${ }^{2}$ For a definition of thinly traded securities see section 2.1 below.

${ }^{3}$ For a literature review prior to 2008 see Hong and Satchell (2014). See also Davidson and Josev (2005), Wang and Jones (2005), Ho and Tsay (2001) and Daves, Ehrhardt and Kunkel (2000).

${ }^{4}$ For a literature review prior to 2007 see Fotis et al. $(2011 ; 74)$. Residual analysis has also been used in the literature in other research areas. See for
}

This paper relates to the above mentioned strands of the literature. Unlike other similar studies (Vazakides 2006; Diacogiannis and Makri 2008), it provides useful insights on the impact of M\&As on competition policy by utilizing event study methodology and investigating four critical phase-II M\&As cleared by the Hellenic Competition Commission (HCC) from 2006 to $2011 .^{5}$

The novelty of this paper lies in the fact that a variety of issues related to the intervalling effect bias is thoroughly examined within a small market such as the ASE, while this examination is conducted during its evolution to maturity. The main reason for choosing the ASE as our benchmark is that it can be characterised as a small emerging market which during the examined period it experienced a huge fall of share prices and thus a considerable number of infrequent trading securities have emerged.

The remainder of this paper is organized as follows. Section 2 presents the sample selection and the research methodology. Section 3 encapsulates the main findings of our analysis, while section 4 concludes the paper. In the Appendix we present the derivation of the employed econometric models.

\section{SAMPLE SELECTION AND MODEL SPECIFICATION}

The sample consists of 22 companies listed in the ASE (three merged entities and 19 competitors) that were active in four phase-II M\&As in Greece during the period 2006-2011. The said M\&As took place in the oil and energy markets as well as in the paper and food industries. ${ }^{6}$

The sample securities exhibit a thick infrequent trading phenomenon. Following Barthdoly, Olson and Peare (2007) this means that they trade more than 80 of trading days or an average of than four days per week. Moreover, a medium traded security trades between $40-80$ and a thin traded security trades less than 40 days per year.

We utilise the models proposed by Scholes and Williams (1977), Dimson (1979), Cohen et al. (1983a)

instance Gleason, Pennathur and Wiggenhorn (2014), Al-Sharkas and Hassan (2010) and Jiang and Leger (2010). An application of residual analysis on antitrust and abuse of dominant position can be found, inter alia, in Fotis (2012). Fotis (2014) explores the unilateral effects of M\&As on competition by using UPP and GUPPI analysis.

${ }^{5}$ Phase - II M\&As require an in depth investigation by the General Directorate for Competition of HCC.

${ }^{6}$ The data are available from the authors upon request. 
and the market model with simple returns ${ }^{7}$ in order to measure the securities' beta systematic risk of the scrutinized sample of firms. ${ }^{8}$ We employ event study methodology and particularly the simple return approach of the market model due to the fact that the crucial interval which we use in order to assess the competitive effects of the M\&As on firm's stock value is almost unaffected by the missing days. That is, the average trading frequency and the number of days between transactions in the time interval are quite high and low respectively. Also, this approach produces unbiased estimates of residuals on the days calculated. $^{9}$

Following the derivation of the econometric models in Appendix and in order to draw some inferences about the validity of the four different methodologies presented there, we use daily security returns and we calculate the mean beta for each firm (merged entity and competitors) evolved in every single phase-II M\&A. The differences between the various methodologies are based on the selection of leads and lags and whether the values of the beta coefficients are estimated simultaneously or independently.

Scholes and Williams (1977) propose the inclusion of only one lag and one lead, while the Dimson (1979) and Cohen et al. (1983a) methodologies are based on the inclusion of many leads and lags. Further, Dimson's model calculates beta coefficient simultaneously, while in Scholes and Williams and Cohen et al. (1983a) models beta coefficients are estimated independently. To give an example, when we apply the Dimson's model, the beta coefficient is estimated by aggregating the slope coefficients of the following regression:

$$
R_{j, t}=a+\sum_{\phi=-L}^{+L} \beta_{j, t+\phi} R_{m, t+\phi}+\varepsilon_{j, t}
$$

On the contrary, the market model does not incorporate lagged and leaded values of market returns and utilises the OLS methodology to estimate the beta coefficient (see equation 1 in the Appendix).

\footnotetext{
${ }^{7}$ The simple returns approach calculates daily returns only for days for which stock prices are available.

${ }^{8}$ The three - factor model (Fama and French 1993) addresses that the time variation in betas is priced, but the size and book-to-market equity effects are still statistically significant. The latter is therefore robust after taking into account the time-variation in beta. However, due to lack of data, the estimation of the three - factor model was not possible.

${ }^{9}$ Unlike the lumped and uniform return approach which underestimate the variance of returns and bias the t-statistics used to calculate the anti or pro completive effects of M\&As. For both approaches as well as adjusted trade-totrade return approach see Fotis and Polemis (2012a), p 186-187.
}

If we allow for the usual assumptions of randomly and independently samples derived from normally distributed populations, then we employ a two tailed pooled variance $t$ - test in order to examine whether the difference between their means is statistically significant. The $\mathrm{t}$ - test can be computed as $t=\frac{\left(\overline{X_{1}}-\overline{X_{2}}\right)-\left(\mu_{1}-\mu_{2}\right)}{\sqrt{S_{p}^{2}\left(\frac{1}{n_{1}}+\frac{1}{n_{2}}\right)}}$ where $S_{p}^{2}=\frac{\left(n_{1}-1\right) S_{1}^{2}+\left(n_{2}-1\right) S_{2}^{2}}{\left(n_{1}-1\right)+\left(n_{2}-1\right)}$ is the pooled variance, $\overline{X_{1}}$ is the mean of sample $1, \overline{X_{2}}$ is the mean of sample 2, $\mu_{1}$ is the mean of population $1, \mu_{2}$ is the mean of population $2, n_{1}$ is the size of sample $1, n_{2}$ is the size of sample 2 . The $t-$ test follows a $t$ distribution with $n_{1}+n_{2}-2$ degrees of freedom.

To test the hypothesis of no difference in the means of two independent populations, the null hypothesis is $H_{0}: \mu_{1}-\mu_{2}=0$ or $\mu_{1}=\mu_{2}$, while the alternative hypothesis is $H_{1}: \mu_{1}-\mu_{2} \neq 0$ or $\mu_{1} \neq \mu_{2}$.

\section{EMPIRICAL RESULTS}

\subsection{Systematic Risk Estimates under Thickly Traded Securities}

Table 1 illustrates the difference between the mean beta generated by the market model and the mean beta provided by employing the models of Scholes and Williams (1977), Dimson (1979) and Cohen et al. (1983a). The beta estimations for each firm are derived from equations (1), (2), (4) and (6) in the Appendix.

From the relevant table it is evident that the null hypothesis is rejected for some phase - II M\&As at $\alpha=0,05$ level of significance (the difference between the mean beta estimated using the simple return approach of market model and the mean beta obtained using the alternative models for each security is statistically significant). Particularly, regarding the phase - II merger 1, the difference between the mean beta coefficient from the market model and the mean beta generated by the Cohen et al. (1983a) model with two leads and lags is statistically significant.

Table 1 also portrays that the models proposed by Scholes and Williams (1977) and Cohen et al. (1983a) improve the biasness of the OLS method (market model) for phase - II M\&As $3 \& 4$. Regarding phase - II M\&As $1 \& 2$ the difference between the mean beta coefficients estimated by using the simple return approach of the market model and the mean beta 
Table 1: Pooled Variance $\mathrm{t}$ - Tests of Equality of Means of Beta Estimations

\begin{tabular}{|c|c|c|c|c|c|}
\hline t- statistics & $\overline{\beta^{S}}=\overline{\beta^{S-W,-1+1}}$ & $\overline{\beta^{S}}=\overline{\beta^{D,-5+5}}$ & $\overline{\beta^{S}}=\overline{\beta^{C,-2+2}}$ & $\overline{\beta^{S}}=\overline{\beta^{C,-3+3}}$ & $\overline{\beta^{S}}=\overline{\beta^{C,-4+4}}$ \\
\hline \hline Phase - II Merger 1 & 1,06 & 2,06 & $2,42^{* *}(0,04)$ & 2,08 & 0,67 \\
\hline Phase - II Merger 2 & 0,68 & 2,20 & 0,67 & 3,26 \\
\hline Phase - II Merger 3 & $-0,37$ & 1,04 & $3,11^{* *}(0,009)$ & $3,31^{* *}(0,006)$ & $3,89^{* *}(0,002)$ \\
\hline Phase - II Merger 4 & $2,28^{* *}(0,04)$ & 1,83 & $2,45^{* *}(0,03)$ & $2,36^{* *}(0,04)$ & $2,51^{* *}(0,03)$ \\
\hline
\end{tabular}

Notes:

$(")=$ statistical significant at $\alpha=0,05$ ( $\mathrm{p}$ - values in parenthesis).

$\overline{\beta^{s}}$ : mean value of beta coefficients derived from simple return approach of market model, $\overline{\beta^{s-W,-1+1}}$ : mean value of beta coefficients derived from Scholes and Williams (1977) model, $\overline{\beta^{D,-5+5}}$ : mean value of beta coefficients derived from Dimson (1979) model, $\overline{\beta^{c,-2+2}}$ : mean value of beta coefficients derived from Cohen et al., (1983a) model with 2 leads and lags, $\overline{\beta^{c,-3+3}}$ : mean value of beta coefficients derived from Cohen et al., (1983a) model with 3 leads and lags, $\overline{\beta^{c,-4+4}}$ : mean value of beta coefficients derived from Cohen et al., (1983a) model with 4 leads and lags.

Source: Authors' elaboration of estimated securities' data.

coefficient obtained using the alternative models is statistically insignificant. ${ }^{10}$

The empirical results for phase - II M\&As $3 \& 4$ contradict the results obtained by the study of Diacogiannis and Makri (2008). They state that for both low and mid cap securities the methods of Scholes and Williams (1977) and Cohen et al. (1983a) do not improve the biasness of the OLS method and conclude that the OLS method is appropriate for beta estimation when the infrequently traded phenomenon is present.

\subsection{Ex-Post Evaluation of Competition Policy for M\&As under Thickly Infrequent Trading Securities}

In this section we proceed to an ex - post evaluation of the four phase - II mergers in order to draw some useful insights regarding competition policy. For this purpose and following the analysis of the previous section we utilize equation (1) in the Appendix for phase - II M\&As $1 \& 2$ and equations (3) and (7) in the Appendix for phase - II M\&As 3 \& 4. Equation (7) is estimated with four leads and lags of market returns. ${ }^{11}$

Phase - II M\&As 1, and 3 consist of firms that are competitors either in horizontal or in vertical level. The firms in phase - II M\&As 2 and 4 are not direct competitors since they are active in neighborhood product markets. Therefore, we group the firms into

\footnotetext{
${ }^{10}$ Except from phase - II merger 1 , where we reject $H_{0}$ derived from Cohen et al. (1983a) with two leads and lags.

${ }^{11}$ The rationale behind the use of equation (7) in the Appendix with 4 leads and lags of market returns is that the estimated $p$ - values of $\overline{\beta^{c, 4+4}}$ for phase $-I I$ mergers 3 and 4 are lower or at least equal than the equivalent estimations of $\overline{\beta^{c,-3+3}}$ and $\overline{\beta^{c,-2+2}}$. Also, since the estimated beta derived from Dimson's model is inconsistent, we do not estimate equation (5) in the Appendix.
}

different levels of competitive interaction so that to infer accurate conclusions of competition policy for M\&As.

For the scope of event study methodology we define various time intervals from one day prior the announcement of the M\&A until the day of the decision by the HCC. Day 0 , denotes the date of: a) the announcement, b) notification, c) the phase-II decision and d) the date of clearness of the M\&A. Short - run time intervals are those that span until 20 trading days before and after each Day 0. Long - run time intervals are those that span from 1 trading day before the announcement until the trading day of the clearness of the M\&A (from 52 to 68 trading days).

We use standard literature so as to calculate Average Abnormal Residual $\left(A A R_{j t}\right)$, Cumulative Average Abnormal Residual $\left(C A A R_{j t}\right.$ ) and Cumulative Abnormal Residual $\left(C A R_{j t}\right.$ ) of security $j$ at period $t$. Thus $A A R_{j t}=\frac{\sum_{j} A R_{j t}}{n}$, where $n$ is the number of the sample securities and $A R_{j t}=R_{j t}-\hat{R}_{j t}$ are the abnormal residuals, where $R_{j t}$ is the actual return of security $j$ at period $t$ and $\hat{R}_{j t}$ is the estimated return derived from equations (1), (3) and (7) in the Appendix. $C A A R_{j t}=\sum_{t=-m}^{+n} A A R_{j t}$, where $m$ is the first day of the time interval and $n$ its last day and $C A R_{j t}=\sum_{t=-m}^{+n} A R_{j t} \cdot{ }^{12}$

We estimate the econometric models over 200 trading days, starting 2 days prior to the various time

\footnotetext{
${ }^{12}$ For the calculation of standard deviation we assume normal abnormal returns. See Maynes and Rumsey (1993).
} 
intervals. For simple return approach of market model the estimation interval of the econometric models is greater than a calendar year.

Table 2 elaborates the short - run competitive effects of the whole sample of M\&As.

From the relevant table, it is evident that the CAAR of both the merged firms and their rivals around the M\&As announcement shows a positive trend for almost all of the time intervals. This outcome constitutes an indication that investors expected the M\&As to be profitable for the rival firms. Duso et al. (2010) have also derived the same outcome for a sample of large M\&As in the European Union during the period 1990 to 2001.

If we restrict our attention to the three days time interval around the merger notification $(-1+1)$, the $C A A R$ continues to be positive, except for the estimated value of the merged entity's $C A A R$, which is calculated by using the simple return approach of the market model. Competitors earn positive gains around the clearness of the examined M\&As, while the merged

Table 2: The Competitive Effects of M\&As: Evidence from the whole Sample (\%)

\begin{tabular}{|c|c|c|c|c|c|c|c|}
\hline \multirow{2}{*}{ Method } & \multirow{2}{*}{$\begin{array}{c}\text { Merger } \\
\text { announcement }\end{array}$} & \multicolumn{2}{|c|}{ All Firms } & \multicolumn{2}{|c|}{ Competitors } & \multicolumn{2}{|c|}{ Merged firms } \\
\hline & & AAR & CAAR & AAR & CAAR & AAR & CAAR \\
\hline \multirow{5}{*}{$R_{j, t}^{S}$} & $-1+1$ & $1,29^{*}$ & 1,13 & $1,33^{*}$ & 0,96 & 1,04 & $2,22^{*}$ \\
\hline & $-5+5$ & $-0,36$ & $-0,40$ & $-0,42$ & $-0,56$ & 0,00 & 0,62 \\
\hline & $-10+10$ & $0,53^{*}$ & $0,07^{*}$ & $0,64^{*}$ & 0,04 & $-0,16$ & 0,20 \\
\hline & $-15+15$ & $-0,20$ & 0,49 & $-0,23$ & 0,46 & $-0,01$ & 0,71 \\
\hline & $-20+20$ & 0,05 & 0,07 & 0,04 & 0,03 & 0,08 & 0,28 \\
\hline \multirow{5}{*}{$R_{j, t}^{S-W}$} & $-1+1$ & $0,92^{*}$ & 0,47 & $1,08^{*}$ & 0,53 & $-0,10$ & 0,13 \\
\hline & $-5+5$ & $-0,17$ & $-0,45$ & $-0,20$ & $-0,63$ & 0,05 & $0,71^{* * *}$ \\
\hline & $-10+10$ & 0,49 & $-0,71$ & 0,58 & $-0,88$ & $-0,11$ & 0,41 \\
\hline & $-15+15$ & $-0,11$ & 0,27 & $-0,13$ & 0,14 & 0,03 & $1,11^{* * *}$ \\
\hline & $-20+20$ & 0,08 & $-0,66$ & 0,07 & $-0,92$ & 0,11 & 0,95 \\
\hline \multirow{5}{*}{$R_{j, t}^{C}$} & $-1+1$ & $-\ddagger$ & $-{ }^{\ddagger}$ & \pm & \pm & $-0,13$ & 0,05 \\
\hline & $-5+5$ & \pm & $-\neq$ & \pm & $-\neq$ & 0,04 & $0,58^{*}$ \\
\hline & $-10+10$ & $-\neq$ & $-{ }^{*}$ & $-\neq$ & $-\neq$ & $-0,12$ & 0,10 \\
\hline & $-15+15$ & $-\neq$ & $-{ }^{*}$ & $-\neq$ & 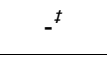 & 0,04 & 0,70 \\
\hline & $-20+20$ & 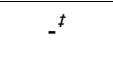 & \pm & $-\neq$ & 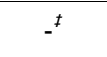 & 0,10 & 0,45 \\
\hline Method & Merger notification & AAR & CAAR & AAR & CAAR & AAR & CAAR \\
\hline$R_{j, t}^{S}$ & $-1+1$ & $-0,41$ & 0,23 & $-0,42$ & 0,24 & $-0,51^{* *}$ & $-0,78^{* * *}$ \\
\hline \multirow[t]{2}{*}{$R_{j, t}^{S-W}$} & $-1+1$ & $-0,13$ & 0,46 & $-0,14$ & 0,48 & $0,07^{* *}$ & $0,27^{* \star *}$ \\
\hline & Phase-Il decision & AAR & CAAR & AAR & CAAR & AAR & CAAR \\
\hline$R_{j, t}^{S}$ & $-1+1$ & $-0,79^{* * *}$ & $-0,81$ & $-0,81^{* * *}$ & $-0,76$ & $-0,70^{* *}$ & $-1,16^{*}$ \\
\hline \multirow[t]{2}{*}{$R_{j, t}^{S-W}$} & $-1+1$ & $-0,94^{*}$ & $-1,10$ & $-1,09^{*}$ & $-1,29$ & 0,05 & 0,10 \\
\hline & Date of Clearness & AAR & CAAR & AAR & CAAR & AAR & CAAR \\
\hline$R_{j, t}^{S}$ & $-1+1$ & 0,68 & $0,62^{* * *}$ & $0,48^{* * *}$ & 0,67 & $-0,13$ & $-0,13$ \\
\hline$R_{j, t}^{S-W}$ & $-1+1$ & $0,75^{* *}$ & 0,95 & $0,55^{* * *}$ & $1,01^{* * *}$ & $-0,55^{* *}$ & $-0,82^{*}$ \\
\hline
\end{tabular}

Notes:

${ }^{\ddagger}$ Even though the results from the Cohen et al., (1983a) model are positive, are not applicable for the purpose of competition policy. The same results we get from all time intervals.

()$\left.^{*}\right)$ statistical significant at $\alpha=0,10,\left(^{* *}\right)=$ statistical significant at $\alpha=0,05,\left({ }^{* * *}\right)=$ statistical significant at $\alpha=0,01$.

Source: Authors' elaboration of estimated securities' data. 
Table 3: The Vertical Effects of Phase - II Merger 1 (\%)

\begin{tabular}{|c|c|c|c|}
\hline \multirow{2}{*}{ Method } & \multirow{2}{*}{ Merger announcement } & AAR & All firms (competitors) \\
\cline { 3 - 4 } & & $5,96^{\cdots *}$ & 4,01 \\
\hline \hline$R_{j, t}^{S}$ & $-1+1$ & $6.02^{*}$ & 3.54 \\
\hline$R_{j, t}^{S-W}$ & $-1+1$ & $6.24^{*}$ & 3.59 \\
\hline$R_{j, t}^{C}$ & $-1+1$ & AAR & CAAR \\
\hline & Merger notification & 0,07 & 0,08 \\
\hline$R_{j, t}^{S}$ & $-1+1$ & $6.02^{* *}$ & 6.23 \\
\hline$R_{j, t}^{S-W}$ & $-1+1$ & $6.24^{* *}$ & 6.45 \\
\hline$R_{j, t}^{C}$ & $-1+1$ & & \\
\hline
\end{tabular}

Notes: See Table 2.

()$\left.^{*}\right)=$ statistical significant at $\alpha=0,10\left({ }^{* *}\right)=$ statistical significant at $\alpha=0,05\left({ }^{* * *}\right)=$ statistical significant at $\alpha=0,01$.

Source: Authors' elaboration of estimated securities' data.

entities loose. However, the decrease of the merged entities' security value does not offset their highly significant positive gains during the three days interval around the announcement of the merger. The positive trend of firms' residuals constitutes an indication that the market is concerned about their possibly anti competitive effects.

Investigating each $M \& A$ independently the empirical results depict that phase II merger 1 show a negative effect at the time of its clearness on firms' security value. However, it is not statistically significant. ${ }^{13}$ Regarding the vertical effects of the said merger on firms' security value we conclude that the merger positively affects the competitors that are active in the various market segments both in the short and the long - run (Table 3). This result is reinforced by the fact that the $A A R$ of all the vertical competitors (except from the estimated value of $A A R$ with simple return approach of market model) is statistically significant with a positive sign. The positive market reaction of vertical competitors indicates that the market is concerned about the anti competitive vertical effects of the merger. ${ }^{14}$

The analysis of the conglomerate effects of phase II merger 2 in Table 4 shows that the examined merger

\footnotetext{
${ }^{13}$ We don't present the empirical results since they are not statistical significant. However, they are available from the authors upon request.

${ }^{14}$ Even though the analysis is restricted to competitors, it is absolutely safe to assume that rivals' reaction is strong enough to make us believe that the examined merger has caused significant anti-competitive effects.
}

increases the efficiency of the merged entity both in the short and the long - run. This implies a cost saving efficiencies effect or pro-competitive effect, that is, lower prices and higher level of competition and consumer welfare. ${ }^{15}$ The same result has been traced to Fotis and Polemis (2012a) in the short - run, but is not in alignment with the result derived by Rahim and Pok (2013).

We derive the same result when we analyse the horizontal effects of phase - II merger 3 during its announcement (Table 5). This result is more evident with Cohen et al., (1983a) model rather than with the other models under scrutiny. In the long - run (52 calendar days from the announcement of the merger) the results are statistical significant for the total sample and particularly for the competitors under scrutiny.

The conglomerate effects of phase - II merger 4 are analysed in Table 6 . The results from the relevant Table depict that the competitors gained from the clearness of the said merger. Both in the short and the long - run (68 calendar days from the announcement of the merger) the CARR is positive, especially the result obtained by the estimation of the

\footnotetext{
${ }^{15}$ In this paper we don't estimate any correlation between firms' security value and consumer welfare. However, the enhancement of the latter constitutes the ultimate goal of competition policy.
} 
Table 4: The Conglomerate Effects of Phase - II Merger 2 (\%)

\begin{tabular}{|c|c|c|c|c|c|c|c|}
\hline \multirow{2}{*}{ Method } & \multirow{2}{*}{ Merger announcement } & \multicolumn{2}{|c|}{ All firms } & \multicolumn{2}{|c|}{ Competitors } & \multicolumn{2}{|c|}{ Merged Firm } \\
\hline & & AAR & CAAR & AAR & CAAR & AR & CAR \\
\hline \multirow{7}{*}{$R_{j, t}^{S}$} & -1 & $-0,50^{* * * *}$ & $-0,50^{* * *}$ & $-0,92^{* * *}$ & $-0,92^{* * *}$ & $0,34^{*}$ & 0,34 \\
\hline & 0 & $-0,46^{* * *}$ & $-0,95^{* * *}$ & $-0,64^{* * *}$ & $-1,56^{* * *}$ & $-0,08$ & 0,26 \\
\hline & +1 & $-0,44^{* * *}$ & $-1,39^{* * * *}$ & $-0,72^{* * * *}$ & $-2,28^{* * *}$ & 0,12 & 0,38 \\
\hline & $-5+5$ & $-0,57$ & $-2,26^{*}$ & $-0,76$ & $-3,94$ & $-0,18$ & $1,11^{*}$ \\
\hline & $-10+10$ & $1,68^{*}$ & $-0,70$ & 2,62 & $-1,43$ & $-0,21$ & 0,78 \\
\hline & $-15+15$ & $-0,78$ & 0,48 & $-1,19$ & $-0,58$ & 0,03 & $2,60^{*}$ \\
\hline & $-20+20$ & 0,85 & 2,87 & 1,17 & 3,54 & 0,22 & 1,53 \\
\hline \multirow{5}{*}{$R_{j, t}^{S-W}$} & $-1+1$ & $-0,44^{* * *}$ & $-1,80^{* * *}$ & $-0,74$ & $-2,94^{* * * *}$ & 0,18 & 0,47 \\
\hline & $-5+5$ & $-0,50$ & $-4,10^{* * *}$ & $-0,72$ & $-6,88^{* * *}$ & $-0,06$ & $1,45^{* * *}$ \\
\hline & $-10+10$ & $1,65^{*}$ & $-3,01$ & $2,53^{*}$ & $-5,27$ & $-0,09$ & $1,52^{* *}$ \\
\hline & $-15+15$ & $-0,91$ & $-1,46$ & $-1,40$ & $-4,12$ & 0,07 & $3,86^{* * *}$ \\
\hline & $-20+20$ & 1,23 & 1,17 & 1,69 & $-0,01$ & 0,29 & $3,53^{* *}$ \\
\hline \multirow{6}{*}{$R_{j, t}^{C}$} & $-1+1$ & $-1,24^{* * *}$ & $-2,57^{* * *}$ & $-2,01^{* * *}$ & $-4,19^{* * *}$ & $0,32^{* * *}$ & $0,67^{* * *}$ \\
\hline & $-5+5$ & $-0,52$ & $-4,26^{* * * *}$ & $-0,73$ & $-6,88^{* * *}$ & $-0,12$ & $0,97^{*}$ \\
\hline & $-10+10$ & $1,63^{*}$ & $-3,32$ & $2,53^{*}$ & $-5,27$ & $-0,15$ & 0,58 \\
\hline & $-15+15$ & $-0,93$ & $-1,93$ & $-1,40$ & $-4,12$ & 0,02 & $2,44^{* *}$ \\
\hline & $-20+20$ & 1,21 & 0,51 & 1,69 & $-0,02$ & 0,24 & 1,58 \\
\hline & Merger notification & AAR & CAAR & AAR & CAAR & AR & CAR \\
\hline$R_{j, t}^{S}$ & $-1+1$ & $-0,05$ & $-0,88^{* * *}$ & $-0,31$ & $-1,77^{* * * *}$ & $0,48^{* * *}$ & $0,88^{* * *}$ \\
\hline$R_{j, t}^{S-W}$ & $-1+1$ & $-0,44^{* * * *}$ & $-1,80^{* * *}$ & $-0,74^{* * *}$ & $-2,94^{* * *}$ & 0,18 & 0,47 \\
\hline \multirow[t]{2}{*}{$R_{j, t}^{C}$} & $-1+1$ & $-1,24^{* * *}$ & $-2,57^{* * *}$ & $-2,01^{* * *}$ & $-4,19^{* * * *}$ & $0,32^{* * *}$ & $0,67^{* * *}$ \\
\hline & $\begin{array}{c}-1 \text { merger } \\
\text { announcement }- \text { merger } \\
\text { notification }\end{array}$ & AAR & CAAR & AAR & CAAR & AR & CAR \\
\hline$R_{j, t}^{S}$ & $-1+4$ & $-0,40^{* * * *}$ & $-1,79^{* * *}$ & $-2,31^{* *}$ & $-3,19$ & $0,29^{*}$ & $0,66^{*}$ \\
\hline$R_{j, t}^{S-W}$ & $-1+4$ & $-0,87^{* * *}$ & $-2,67^{* * *}$ & $-2,31 *$ & $-3,54$ & $0,26^{*}$ & $0,73^{* *}$ \\
\hline \multirow[t]{2}{*}{$R_{j, t}^{C}$} & $-1+4$ & $-0,88^{* * *}$ & $-2,72^{* * *}$ & $-2,31^{* *}$ & $-3,54$ & 0,23 & $0,56^{*}$ \\
\hline & $\begin{array}{c}-1 \text { merger } \\
\text { announcement }- \text { date of } \\
\text { merger clearness }\end{array}$ & AAR & CAAR & AAR & CAAR & AR & CAR \\
\hline$R_{j, t}^{S}$ & $-1+68$ & $-0,91$ & $-9,58$ & $-1,54$ & $-15,59$ & 0,34 & 2,44 \\
\hline$R_{j, t}^{S-W}$ & $-1+68$ & $-0,75$ & $-2,23$ & $-1,33$ & $-7,06$ & 0,42 & $7,43^{* * * *}$ \\
\hline$R_{j, t}^{C}$ & $-1+68$ & $-0,77$ & $-3,48$ & $-1,34$ & $-7,14$ & 0,37 & $3,85^{*}$ \\
\hline
\end{tabular}


Table 5: The Horizontal Effects of Phase - II Merger 3 (\%)

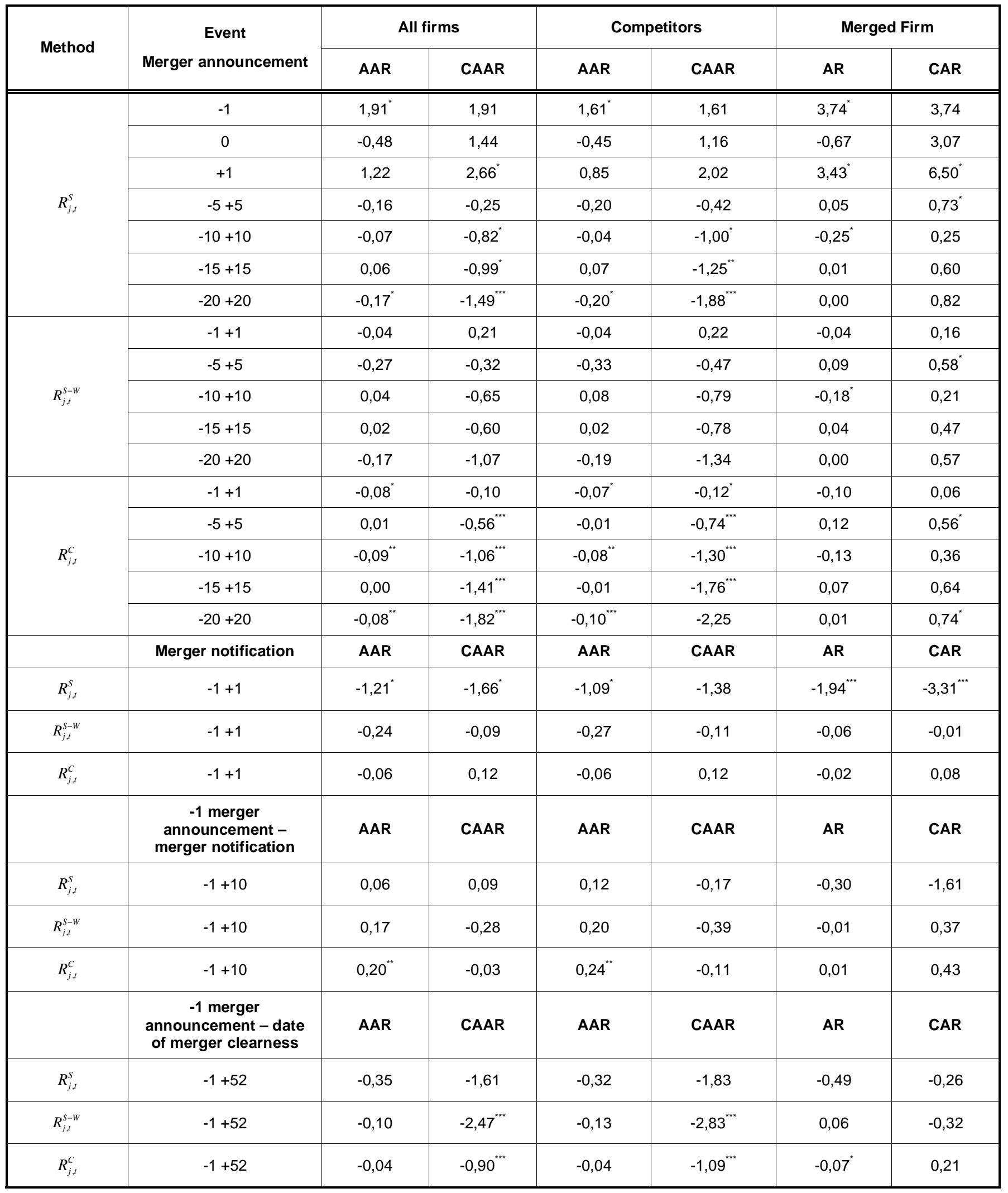


Table 6: The Conglomerate Effects Phase - II Merger 4 (\%)

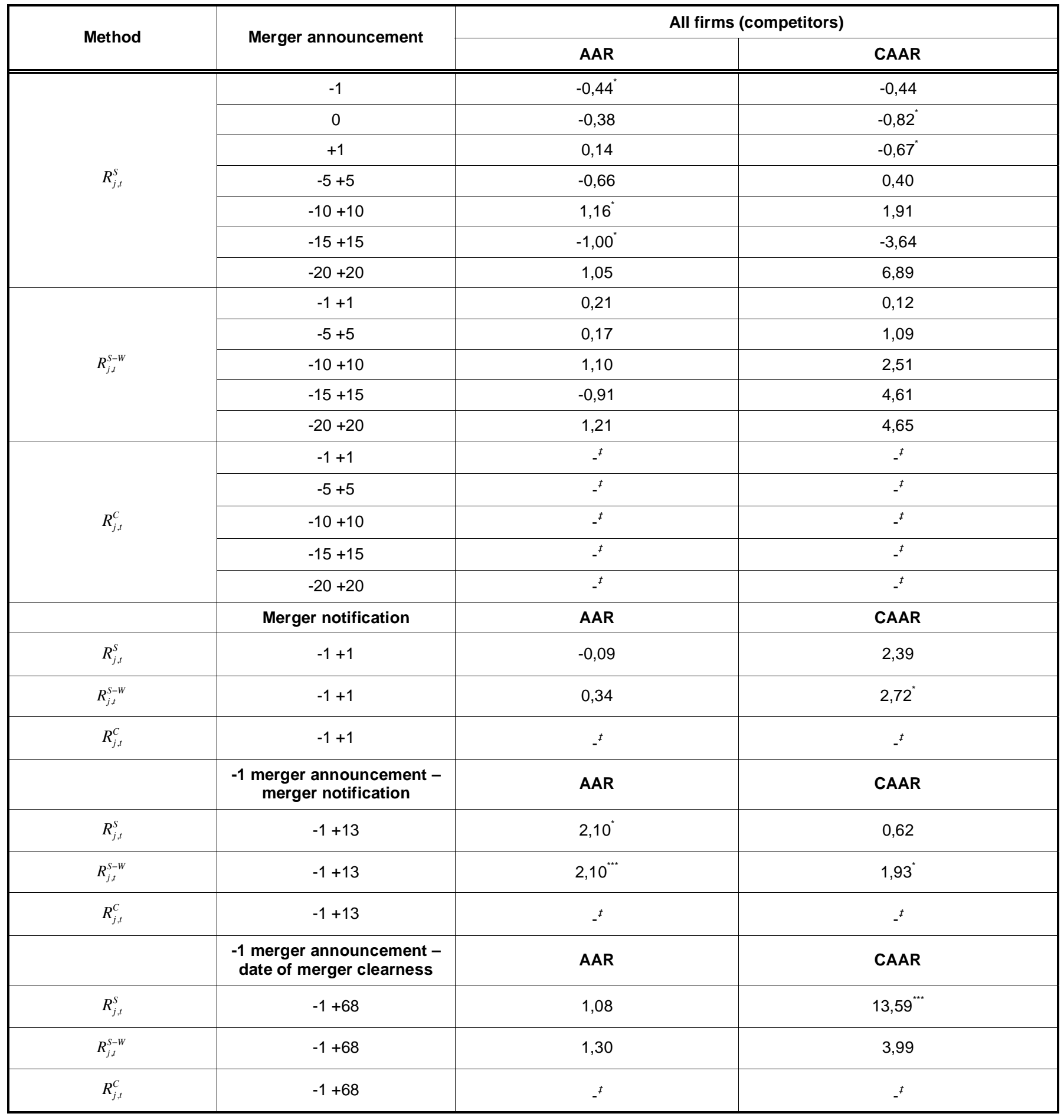

Note: See Table 2.

Source: Authors' elaboration of estimated securities' data.

Cohen et al., (1983a) model. Therefore, the merger under examination caused anti competitive effects.

\section{CONCLUSIONS}

This paper applies different empirical methodologies in order to measure the security's systematic risk relating to the temporally corresponding market return. It also explores possible anti or pro competitive effects of four phase II M\&As that took place in Greece during the period from 2006 to 2011 . For this scope we apply event study methodology in different empirical models in a sample of firms listed in the ASE with thickly infrequent trading securities. We assess four beta 
evaluating models developed by Scholes and Williams (1977), Dimson (1979), Cohen et al. (1983a) and Maynes and Rumsey (1993).

The empirical results indicate that the models by Scholes and Williams (1977) and Cohen et al. (1983a) improve the biasness raised from the application of the OLS method. It is worth mentioning that, when we use the Dimson's methodology the difference between the estimated betas is not statistically significant.

The applied ex post evaluation of competition policy in the whole sample depicts that competitors gain while merged entities loose (or at least do not gain) from the clearness of the scrutinized M\&As in the short - run. This result indicates decreased efficiency for the merged firms and enhanced profitability for the competitors.

However, if we focus our attention on each individual phase - II M\&A, the results are rather controversial. More specifically, phase - II merger 1 positively affects competitors that are active in different levels of production in the short - run (vertical anti competitive effects), while phase - II M\&As 2 \& 3 positively affect the level of competition in the relevant product markets both in the short and long - run (conglomerate and horizontal pro competitive effects correspondingly). Moreover, the clearness of phase - II conglomerate merger 4 restricts the level of competition in the relevant product markets.

\section{ACKNOWLEDGEMENT}

This paper benefits from the valuable comments of the participants of the $1^{\text {st }}$ International Conference of Business and Economics, Hellenic Open University, 67 February, Athens, Greece. We are solely responsible for its errors.

\section{APPENDIX}

\section{Derivation of econometric models}

Following Maynes and Rumsey (1993), Fotis et al. (2011) and Fotis and Polemis (2012a) the market model forecasts that firm is security simple return at time $t\left(R_{j, t}^{S}\right)$ is proportional to a market return. That is,

$R_{j t}^{S}=a+\beta^{S} R_{m, t}+\varepsilon_{j t}$

where $R_{m t}$ is the return on the market index for the day $t$ and $\beta^{s}$ the beta coefficient of simple return market model.
Scholes and Williams (1977) have indicated that beta coefficients are downward biased for infrequently traded securities and they are upward biased for very frequently traded securities. They proposed a consistent estimator of beta which is given by equation (2):

$\beta^{S-W}=\frac{\beta_{j t}^{-1}+\beta_{j t}^{0}+\beta_{j t}^{+1}}{\left(1+2 \rho_{m t}\right)}$

where $\beta_{j t}^{-1}, \quad \beta_{j t}^{0}$ and $\beta_{j t}^{+1}$ are estimates of beta coefficient from the regression between the observed security return and market index return at $t=-1, t=0$ and $t=+1$ respectively and $\rho_{m t}$ is the firstorder serial correlation coefficient of market returns.

Given equations (1) and (2), the market model becomes,

$R_{j t}^{S-W}=a+\beta^{S-W} R_{m t}+\varepsilon_{j t}$

Dimson (1979) advocates that the return on a specific security depends on past, present and future returns of the market portfolio. Dimson's beta coefficient is given in equation (4):

$\beta^{D}=\sum_{\phi=-L}^{+L} \beta_{j t+\phi}$

where $\phi=-L \ldots \ldots+L$ are lagged, contemporaneous and leading estimated values of beta coefficient. Substituting equation (4) into equation (1), we calculate firm $j$ 's security return at time $t\left(R_{j t}^{D}\right)$ :

$R_{j t}^{D}=a+\beta^{D} R_{m t}+\varepsilon_{j t}$

The Cohen et al. (1983a) model (see also Cohen et al. (1983b), as opposed to the Scholes and Williams (1977) models, utilizes many leads and lags of the market portfolio's return so as to produce an efficient beta coefficient. Cohen et al. (1983a) and Fowler and Rorke (1983) argue that the beta estimator of Dimson's model generates inconsistent estimates. Cohen et al. (1983a) proposed a consistent estimator, which is given by equation (6):

$$
\beta^{C}=\frac{\beta_{j t}+\sum_{\phi=1}^{L} \beta_{j t+L}+\sum_{\phi=1}^{L} \beta_{j t-L}}{\left(1+\sum_{\phi=1}^{L} \rho_{m t+L}+\sum_{\phi=1}^{L} \rho_{m t-L}\right)}
$$

where $\rho_{m t+L}$ and $\rho_{m t-L}$ are the $L$ - order serial correlation of market portfolio's returns and $-L,+L$ 
imply lagged and leading values of $L$. Substituting equation (6) into equation (1), we calculate firm is security return at time $t\left(R_{j t}^{C}\right)$ :

$$
R_{j t}^{C}=a+\beta^{C} R_{m t}+\varepsilon_{j t}
$$

\section{REFERENCES}

Armitage Seth and Janusz Brzeszczynski. 2011. "Heteroscedasticity and Interval Effects in Estimating Beta: UK Evidence." Applied Financial Economics 21(20):1525-1538. http://dx.doi.org/10.1080/09603107.2011.581208

Aktas, Nihat, Eric de Bodt and Richard Roll. 2007. "European M\&A Regulation is Protectionist." The Economic Journal 117:1096-1121. http://dx.doi.org/10.1111/j.1468-0297.2007.02068.x

Al-Sharkas, Adel A and Kabir M Hassan. 2010. "New Evidence on Shareholder Wealth Effects in Bank Mergers during 19802000." Journal of Economics and Finance 34(3):326-348. http://dx.doi.org/10.1007/s12197-008-9071-1

Barthodly, Jan, Dennis Olson and Paula Peare. 2007. "Conducting Event Studies on a Small Stock Exchange." The European Journal of Finance 13(3):227-252. http://dx.doi.org/10.1080/13518470600880176

Bharba Gurmeet Singh. 2008. "Potential Targets: An Analysis of Stock Price Reaction to Acquisition Program Announcements." Journal of Economics and Finance 2(2):158-175.

Cohen, J Kalman, Gabriel A Hawawini, Steven F Maier, Robert A Schwartz, and David K Whitcomb. 1983b. "Estimating and Adjusting for the Intervalling- Effect Bias in Beta." Managerial Science 29:135- 148. http://dx.doi.org/10.1287/mnsc.29.1.135

Cohen, J Kalman, Gabriel A Hawawini, Steven F Maier, Robert A Schwartz, and David K Whitcomb. 1983a. "Friction in the Trading Process and the Estimation of Systematic Risk." Journal of Economics and Finance 12:263- 278 http://dx.doi.org/10.1016/0304-405X(83)90038-7

Cox, J Alan. and Jonathan Portes. 1998. "Mergers in Regulated Industries: The Uses and Abuses of Event Studies." Journal of Regulation and Economics 14:281-285. http://dx.doi.org/10.1023/A:1008087424850

Daves, R Phillip, Michael C Ehrhardt, and Robert A Kunkel. 2000. "Estimating Systematic Risk: The Choice of Return linterval and Estimation Period." Journal of Financial and Strategic Decisions 13:7-13.

Davidson Sinclair and Thomas Josev. 2005. "The Impact of Thin Trading Adjustments on Australian Beta Estimates." Accounting Research Journal 18(2):111 - 117. http://dx.doi.org/10.1108/10309610580000679

Diacogiannis George and Paraskevi Makri. 2008. "Estimating Betas in Thinner Markets: The Case of the Athens Stock Exchange." International Research Journal of Finance and Economics 13:108-122.

Dimson Elroy. 1979. "Risk Measurement when Shares are Subject to Infrequent Trading." Journal of Financial Economics 7:197226. http://dx.doi.org/10.1016/0304-405X(79)90013-8

Duso, Tomaso, Damien J Neven and Lars-Hendrik Röller. 2007. "The Political Economy of European Merger Control: Evidence Using Stock Market Data." Journal of Law and Economics 50(3):455-489. http://dx.doi.org/10.1086/519812

Duso, Tomaso, Klaus Gugler and Burcin Yurtoglou. 2010. "Is the Event Study Methodology Useful for Merger Analysis? A Comparison of Stock Market and Accounting Data." International Review of Law and Economics 30:186-192. http://dx.doi.org/10.1016/j.irle.2010.02.001
Fama F Eugene. 1970. "The Behavior of Stock Market Prices." Journal of Business 38:34-105. http://dx.doi.org/10.1086/294743

Fama F Eugene and Kenneth R French. 1993. "Common risk factors in the returns on stocks and bonds." Journal of Financial Economics 33:3-56 http://dx.doi.org/10.1016/0304-405X(93)90023-5

Fotis, Panagiotis. 2012. "Competition Policy \& Firm's Damages." Pp. 116-139 in Recent Advances in the Analysis of Competition Policy and Regulation, edited by Y. Katsulakos and J. E. Harrington, London UK. http://dx.doi.org/10.4337/9781781005699.00012

Fotis Panagiotis. 2014. "Economic Tools for Merger Appraisal: A Theoretical and Empirical Standpoint." Journal of Reviews on Global Economics 3:24-32.

Fotis Panagiotis and Michael Polemis. 2011. "The Use of Economic Tools in Merger Assessment." European Competition Journal 7(2):323-347.

Fotis Panagiotis and Michael Polemis. 2012a. "The Short - Run Competitive Effects of Merger Enforcement." European Competition Journal 8(1):183-210. http://dx.doi.org/10.5235/174410512800370025

Fotis, Panagiotis, Michael Polemis and Nikolaos Zevgolis. 2011. "Robust Event Studies for Derogation from Suspension of Concentrations in Greece During the Period 1995-2008." Journal of Industry Competition and Trade 11(1):67-89. http://dx.doi.org/10.1007/s10842-010-0070-5

Fowler, J David and Harvey C Rorke. 1983. "Risk Measurement when Shares are Subject to Infrequent Trading: Comment." Journal of Financial Economics 12:279- 283. http://dx.doi.org/10.1016/0304-405X(83)90039-9

Gleason, Kimberly, Anita Pennathur and Joan Wiggenhorn. 2014. "Acquisitions of Family Owned Firms: Boon or Bust?." Journal of Economics and Finance 38(2):269-286. http://dx.doi.org/10.1007/s12197-011-9215-6

Ho Li-Chin Jennifer and Jeffrey J Tsay. 2001. "Option trading and the intervaling effect bias in beta." Review of Quantitative Finance and Accounting 17:267-282. http://dx.doi.org/10.1023/A:1012292626308

Hong KiHoon Jimmy and Steve Satchell. 2014. "The sensitivity of beta to the time horizon when log prices follow an OrnsteinUhlenbeck process." The European Journal of Finance 20(3):264-290. http://dx.doi.org/10.1080/1351847X.2012.698992

Jiang Fei and Lawrence A Leger. 2010. "The Impact on Performance of IPO Allocation Reform: An Event Study of Shanghai Stock Exchange A-shares." Journal of Financial Economic Policy 2(3):251-272

http://dx.doi.org/10.1108/17576381011085458

Levhari David and Haim Levy. 1977. "The Capital Asset Pricing Model and the Investment Horizon." The Review of Economics and Statistics 59(1):92-104. http://dx.doi.org/10.2307/1924908

Maynes Elizabeth and John Rumsey. 1993. "Conducting Event Studies with Thinly Traded Stocks." Journal of Banking and Finance 17:145-157. http://dx.doi.org/10.1016/0378-4266(93)90085-R

Milonas Nikolaos and Gerasimos Rompotis. 2013. "Does Intervalling Effect Affect ETFs?." Managerial Finance 39(9):863-882. http://dx.doi.org/10.1108/MF-01-2010-0004

Mueller C Dennis 1980. "The Determinants and Effects of Mergers: An International Comparison." Cambridge, MA, Oelgeschlager, Gunn \& Hain.

Rahim Nurhazrina Mat and Wee Ching Pok. 2013. "Shareholder Wealth Effects of M\&As: the third wave from Malaysia." International Journal of Managerial Finance 9(1):49-69. http://dx.doi.org/10.1108/17439131311298520 
Scholes Myron and Joseph Williams. 1977. "Estimating Betas from Nonsynchronous Data." Journal of Financial Economics 5:309-328. http://dx.doi.org/10.1016/0304-405X(77)90041-1

Sercu, Piet, Martina L Vanderbroek and Tom Vinaimont. 2008. "Thintrading Effects in Beta: Bias v. Estimation Error." Journal of Business Finance \& Accounting 35(9):1196-1219. http://dx.doi.org/10.1111/j.1468-5957.2008.02110.x
Vazakides Athanasios. 2006. "Testing Simple Versus Dimson Market Models: The Case of the Athens Stock Exchange." International Research Journal of Finance and Economics 2:26-34.

Wang Peijie and Trefor Jones. 2005. "A Different Approach to Estimating Betas of Securities Subject to Thin Trading and Serial Correlation." Applied Financial Economics 15(16):1145-1152.

http://dx.doi.org/10.1080/09603100500359773

DOI: http://dx.doi.org/10.6000/1929-7092.2015.04.09

(C) 2015 Fotis et al.; Licensee Lifescience Global.

This is an open access article licensed under the terms of the Creative Commons Attribution Non-Commercial License (http://creativecommons.org/licenses/by-nc/3.0/) which permits unrestricted, non-commercial use, distribution and reproduction in any medium, provided the work is properly cited. 